This item was submitted to Loughborough's Research Repository by the author.

Items in Figshare are protected by copyright, with all rights reserved, unless otherwise indicated.

\title{
Safety and security of remote monitoring and control of intelligent home environments
}

PLEASE CITE THE PUBLISHED VERSION

PUBLISHER

(c) IEEE

VERSION

VoR (Version of Record)

LICENCE

CC BY-NC-ND 4.0

\section{REPOSITORY RECORD}

Yang, Lili, Shuang-Hua Yang, and Fang Yao. 2019. "Safety and Security of Remote Monitoring and Control of Intelligent Home Environments". figshare. https://hdl.handle.net/2134/4134. 
This item was submitted to Loughborough's Institutional Repository (https://dspace.lboro.ac.uk/) by the author and is made available under the following Creative Commons Licence conditions.

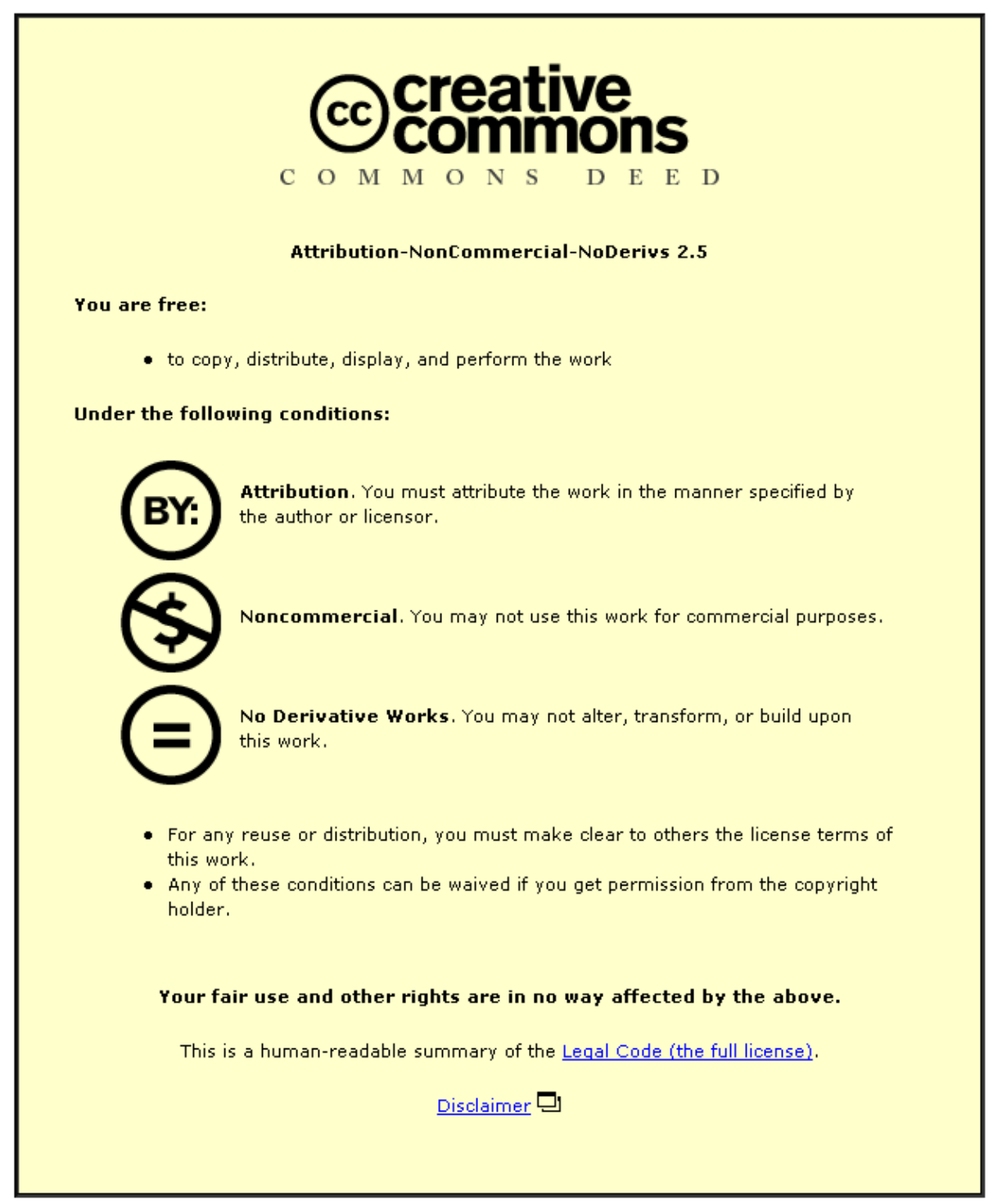

For the full text of this licence, please go to: http://creativecommons.org/licenses/by-nc-nd/2.5/ 


\title{
Safety and Security of Remote Monitoring and Control of intelligent Home Environments
}

\author{
Lili Yang, Shuang-Hua Yang (SMIEEE), and Fang Yao
}

\begin{abstract}
Intelligent home environments are one of the major application areas of pervasive computing. Safety and security are two most important issues in the remote monitoring and control of intelligent home environments. This article takes safety and security into consideration together and proposes a phone-out-only policy for ensuring security and virtual home environments for safety. A remote monitoring and control system for a security camera is used to illustrate the new methodologies for safety and security. By using the demonstration system people are able to easily monitor and control a security camera, central heating, microwave oven and washer from anywhere by using mobile phones. Our system distinguishes from the existing DTI (Department of Trade and Industry in the UK) next wave technologies and a few of on-going EU projects in the ways of dealing with safety and security and its simplicity. Remote monitoring and control of intelligent home environments can be of great benefits to the working families and holiday makers and has a great commercial potential.
\end{abstract}

\section{INTRODUCTION}

\subsection{Intelligent home environments}

A $\mathrm{n}$ intelligent home environment or a smart home is a $A$ home or building that is equipped with special structured wiring (wired or wireless) to enable occupants to remotely control or program an array of automated home electronic devices by entering a single command. For example, a homeowner on vacation can use a Touchtone phone to arm a home security system, control temperature gauges, switch appliances on or off, control lighting, program a home theatre or entertainment system, and perform many other tasks.

Traditional home devices are static and only can be operated manually. People always go to the front of devices to operate, such as central heating, microwave oven, television and so on. The problem for the traditional home devices is that people have to take care of status of devices and make adaptation if it is necessary. When one feels it is cold during night, he/she has to get up and turn on the central heating. When one opens the window in the morning and leave out without turning off the central heating, he/she has to go back to turn off the central heating, otherwise the heating is wasted, and unfortunately this will cause a high bill. Intelligent home can be helpful in this situation. People control those devices

Lili Yang, Shuang-Hua Yang and Fang Yao are with the Computer Science Department at Loughborough University, Loughborough, Leicestershire, LE11 3TU (phone: 00441509 222328; fax: 00441509 211586; e-mail: l.yang@1boro.ac.uk). via cell phone, computer, or switch instead of doing it on their own. So the definition of intelligent home is "a dwelling incorporating a communications network that connects the key electrical appliances and services, and allows them to be remotely controlled, monitored, or accessed" [1].

The concept of intelligent home is like a server-client model. There should be a server in the "centre" of home. This server communicates with other devices. Actually, these devices have been made networked-enable. The difference between these devices from traditional devices is that they have ability to receive digital signals from servers and transfer these digital signals as control signals. A television can receive program from the Internet with the help of a digital chip, a washer can start to work by receiving commands from a server, and a recorder can record program at a setting time. All these can happen automatically without house holders being at home.

For users, what they need is a controller, which should provide with the capability of computing, storing data, sending signals through a cable or wireless. Considering about the requirement of a controller, mobile phones are a suitable option as a remote controller. A certain level of computing, limited memory and improved battery have been standard settings for mobile phones in the market.

Intelligent home environments can work in many other fields such as healthcare, entertainment, improving zoology environments and saving energy. Fig. 1 illustrates the use of intelligent home environments.

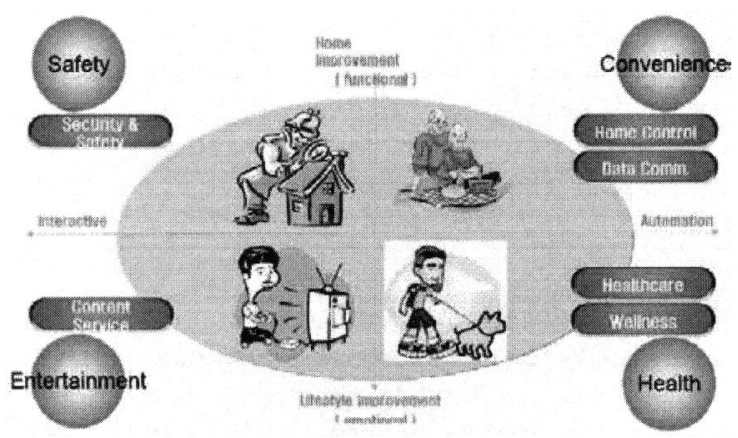

Fig. 1. Intelligent home service [2]

\subsection{On-going relative projects}


A key element of an intelligent home environment will be a connection of the Internet, since this not only gives occupants access to new and emerging Internet services such as online shopping and banking and email service, but it also opens up the possibility of remote monitoring and control of home systems. Latest research in the wireless and mobile market is focused on accessing the Internet and email from anywhere. None of the current providers can declare that monitoring and controlling your home environments is possible from any remote location.

The DTI next wave technologies [3] and the European commission funded Information Society Technologies (IST) work programme [4] are two major drivers in the related technology development. The Department of Health in the UK has been also contributing in the home telecare systems [5]. Because of the huge potential markets a number of research and commercial projects are on-going in this area. Various significant progresses have been achieving in home network communication protocol such as EHS (European home systems) [6], home network gateway development such as FG (flexible gateway) developed by EA Technology [7] and Trialog's EHS OSGi (open service gateway initiative) Bundle [8], and demonstration systems such as the EIB (European Installation Bus) based integrated system installed in a building located in South West London [9], and the Advantica demonstration house located at Loughborough [10].

\subsection{Focus of this paper}

Many of the above existing technologies and demonstration systems are very powerful and versatile, but difficult to set up, too expensive for the homes market, and attackable from outside. Trust is at the heart of all successful business relationships, both in the physical world and on-line, ensuring their longevity and stability. User confidence is essential to the development of technologies for the remote monitoring and control of intelligent home environments and markets. If people do not believe that the technologies will not only deliver a certain quality of desired basic functionality and services, but also absolutely secure their home, protecting it from unwanted eyes, then they will not purchase them. This paper is focused on the simplicity, safety and security of the system which distinguish from the DTI next wave technologies and the EU IST work programme.

This paper is structured as follows. Section 2 presents similarities of safety and security. Our safety and security methodologies are presented in Section 3. The implementation of the remote monitoring and control system for our intelligent home environment is introduced in Section 4. Section 5 gives the commercial potential of our technologies. Finally Section 6 concludes this paper.
The safety risk analysis has the aim of specifying the safety requirements of the system. The security risk analysis identifies the potential security problems. There are some differences but more similarities between safety and security properties [11]. For example, in security the weaknesses in a system and dangers are called vulnerabilities and threats, in safety they are called failure mechanisms and hazards, but they can be considered to be alike. In security examples the countermeasures that need to be put in place to counter the risks are access controls, fire walls, etc., in safety they are redundancy, protective equipments, monitoring devices, etc. Rushby [12] presented the nature of safety and security, in which the differences between the two were recognised, but also both groups subscribe to similar development techniques, i.e. safety and security techniques could be applicable to each other's domains. Security could benefit from fault tolerant approaches typically found in safety techniques, and that security system developers might benefit from a greater understanding of the hazard analysis methods used by safety engineers.

In general, safety, security and their associated risk analysis techniques are closely related. Both deal with risks and both result in constraints, which may be regarded as negative requirements. Both involve protective measures, and both produce requirements that are considered to be of the greatest importance. These similarities indicate that some of the techniques applicable to one field could also be applicable to the other [13].

\section{SAFETY AND SECURITY OF REMOTE MONITORING AND CONTROL OF INTELLIGENT HOME ENVIRONMENTS}

\subsection{System architecture}

The architecture of our system is shown in Fig. 2, which comprises an outdoor part and an indoor part. The outdoor part is a mobile phone (or a PDA) equipped with a specially designed GUI (Graphic User Interface). The indoor part includes a broadband modem, a home portal (or called home server), and a wireless home network. The broadband modem maintains a permanent Internet connection. Our technology and innovation focus on the safety and security of remote monitoring and control which run at the home portal.

The information of devices is stored in an XML file which includes device names, link address, and name of manufacturer. The application communicates with a server and gets XML file to show on the screen. The server manages the devices and records the current state of the devices into a XML file. If a mobile phone connects to the server, the latest information of devices can be gained immediately.

\section{SIMILARITIES OF SAFETY AND SECURITY}




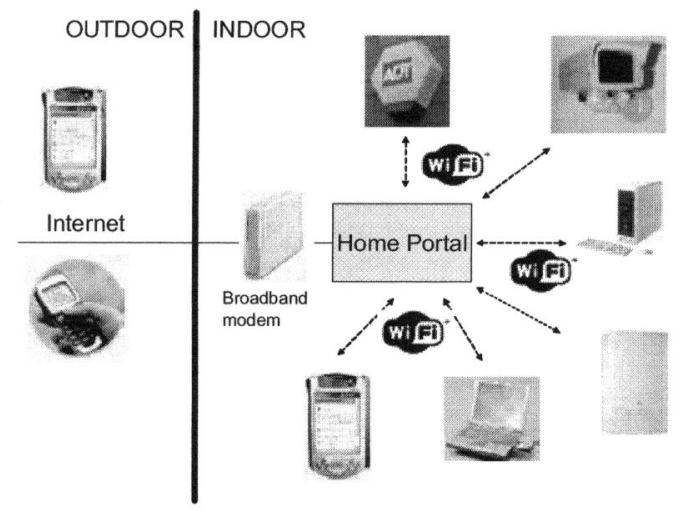

Fig. 2. Remote monitoring and control of intelligent home environments

\subsection{Safety and security methodology}

There will be never absolutely safe and secure to a home environment if a remote user is allowed to directly access to the home environment and make any adjustment to its control system. In the opposite way, there will be no remote monitoring and control if a remote user is not allowed to access the home environment and adjust its control system. Our methodology is based on a phone-out-only policy and a virtual home environment in order to ensure the safety and security.

In an emergency situation such as home intrusion or fire accident the indoor part of the system will automatically transmit an alarm message to selected individuals by telephone, text message, or email. In order to minimize the number of false alarms while maximizing the chances of a real alarm being detected the selected individuals have an opportunity to check the real situation and cancel a false alarm. The 'phone-out-only' policy assures that the direct communication between the remote users and the real home environments can be initiated only by the intelligent home appliances from the indoor side rather than by the remote users from the outdoor side.

The virtual home environment is introduced to act as a mediate between the remote users and the intelligent home environment. Any authorized remote user can have direct access to the virtual home environment, but not to the real home. The virtual home environment is designed firstly to check whether a remote monitoring and control command is safe or not, secondly to respond various requests from an authorized remote user. If the control command from the remote user does not tempt to do any harm to the real home environment and the control command was sent from a certain pre-selected telephone numbers, this control command can be applied to the real home environment, otherwise the remote control command will be rejected.

Information exchange between the virtual home environment and the real home environment regularly updates the virtual home environment in order to represent the real situation. The methodology is shown in Fig. 3, a simple version of Fig. 2.

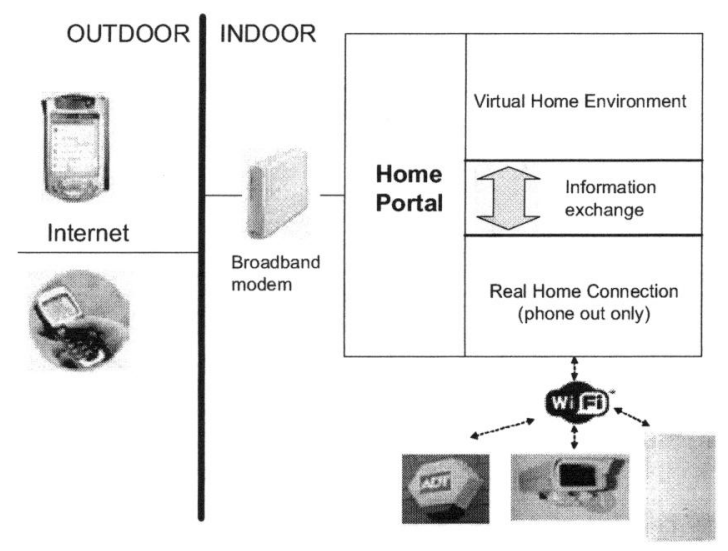

Fig. 3. Safety and security methodology

Our system is expected to have a quick response to any authorized user requests. Because of introducing both the 'phone-out-only' policy and the virtual home environment our system is safe and secure. The home portal like a satellite receiver at home is the only extra equipment the customers need. Our system is cheap and low cost. The innovation encompasses extraordinary markets through the next generation of intelligent and Internet-enabled home appliances.

\section{DEMONSTRATION SYSTEM}

Our demonstration system is a mobile phone based remote monitoring and control system, which can operate a security camera, central heating, microwave oven, and washer. In this section we only demonstrate the mobile phone user interface and various functions implemented for home appliances. The phone-out-only policy and virtual environments have been implemented in the home portal as shown in Fig. 3.

\subsection{User interface}

The initial screen of the mobile phone user interface is a text list of available services on the home portal as shown in Fig. 4.a. A list of available intelligent home appliances is launched from the selection of the initial screen as shown in Fig. 4.b. If a user selects the security camera service, he/she will get a list of the screen size of images (shown in Fig. 4.c). After choosing an image size and pressing "OK", users should be allowed to input the IP address of camera. There is a default IP address which is shown in the text field. 


\subsection{Central heating in use}

After choosing appropriate settings, the server will provide user confirmation of these settings and the current states of the home devices. For example, a user has chosen "winter setting", temperature 48, starting time 15 Sep 2005 13:04:00 and ending time 29 Sep 2005 13:04:00. The current state of the central heating is 'on'. Fig. 5 gives all the information.

\subsection{Security camera in use}

The security camera can be controlled by using four direction keys of a mobile phone or by a menu. Fig. 6 illustrates the image displayed in a mobile phone and the control menu. Fig. 7 shows two images after moving the screen to left.

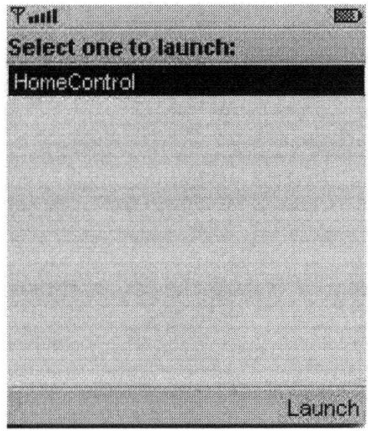

(a) initial screen

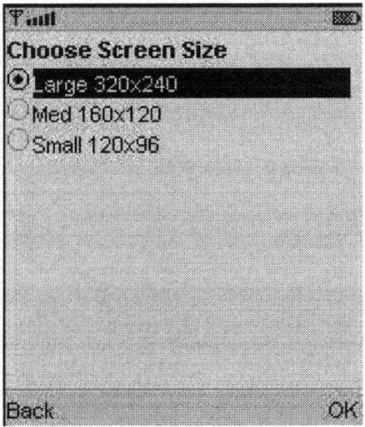

(c) screen size

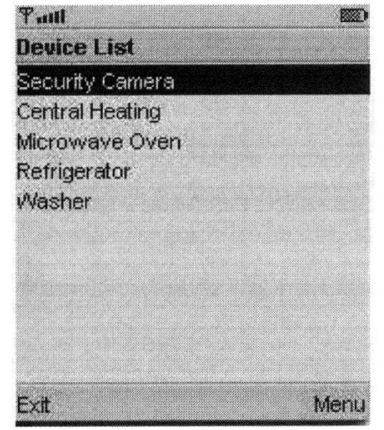

(b) available services

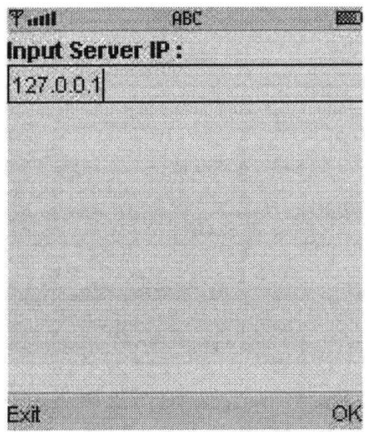

(d) link with the home portal
Fig. 4. Mobile phone user interface

\section{COMMERCIAL POTENTIAL}

Remote monitoring and control of intelligent home environments can be of great benefit to the working families and holiday makers. The remote monitoring and control systems of intelligent home environments are fully automated and can transmit an alarm message to selected individuals by telephone, text message or email to provide [14]:

- $\quad$ Peace of mind, by immediately notifying home owners of any security incident
- Personal safety, by alerting neighbours and friends in the event of fire or personal attack

- Wider protection, by warning of water and gas leaks and power failure to key appliances

- Child safety, by sending messages to indicate when children return home

- Elderly relative safety, by warning to problems such as fall

Convenience, by being able to remotely monitor and control over the Internet from anywhere in the world the home's burglar alarm and Internet appliances.

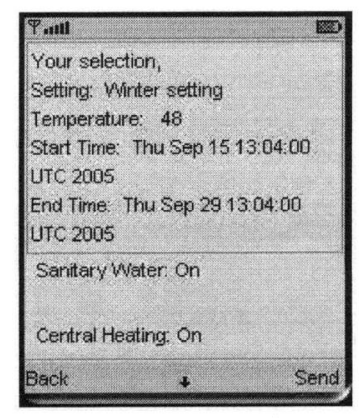

Fig. 5. Central heating in use

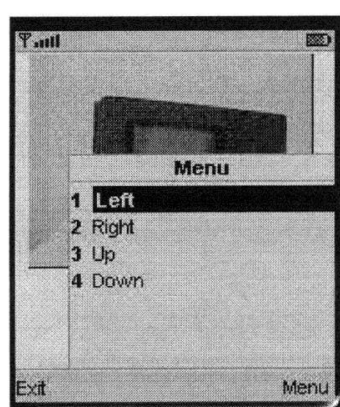

Fig. 6. Direction menu of security camera
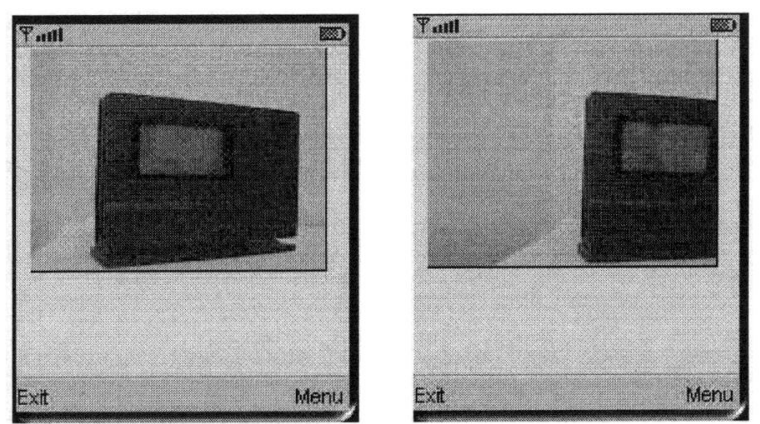

Fig. 7. Moving the image to left

DTI next wave technologies web site [15] presents some of the statistics and predictions underlining the commercial potential of these sorts of technologies for smart homes:

- Over 7 billion microprocessors were sold in 2001, only $2 \%$ of which were destined for PCs the rest are incorporated into a range of more-or-less "dumb" devices.

- By 2005 there will be 2 bn mobile customers, at least $25 \%$ of whom will engage in $\mathrm{m}$-commerce.

Projections for the value of our remote monitoring and control system of intelligent home environments delivered over these devices and services vary widely but are significant. There is a great opportunity for our system to be adopted by the market. 


\section{CONCLUSIONS}

The concept of Intelligent Home Environments appears recently. It substantially represents the advantages of network technology combining with web service and the Internet. Controlling electronic products from outside or other places in a house, or seeing what is happening in the home from anywhere can make facility to users. This paper describes the concept of Intelligent Home Environment. In order to ensure the safety and security of the remote monitoring and control systems this paper proposes a phone-out-only policy and a virtual environment strategy. A demonstration system is established to illustrate the concept of remote monitoring and control of intelligent home environments. This paper also presents the commercial potential of our technologies, which most of academic papers normally do not consider.

\section{REFERENCES}

[1] King, N, 2003, Smart Home - A Definition, available in http:/Www.changeagentteam.org.uk/library/docs/Housing/smarthome pdf

[2] Yoon. M. H, 2004, Intelligent Home in Korea, available in http//www.tieke.fi/mp/db/file library/x/IMG/12864/file/10 Korea $S$ martHome.pdf

[3] Available in http://www.nextwave.org.uk

[4] Available in http://europa.eu.int/information society/index en.htm

[5] Available in http:/www.dh.gov.uk

[6] Available in http:/www.domotics.com/homesys/HSpapers/EHSproto.htm\#ST7537HS 1

[7] Available in

http//www.nextwave.org.uk/downloads/network home 5643.pdf

[8] Available in http:/www.trialog.com/Pdf/EhsOsgiBundle.pdf

[9] Bromley K. and Perry M., 2001, Open systems in action, Building Service Journal.

[10] Available in http:/www.advantica.biz/certserv/other services autumn 04.htm

[11] Rushby, J., 1994, Critical properties: survey and taxonomy, Reliability Engineering and System Safety, 43, 182-219.

[12] Eames, D. P. and Moffett, J., 1999, The integration of safety and security requirements, Lecture Notes in Computer Science, 1698, 468-480.

[13] Yang, L., and Yang, S.H., 2005, Ensure the safety and security for Internet based control systems, Measurement + Control, 1, 22-26.

[14] Available in http://www.wi-fiplanet.com

[15] Available in http://www.nextwave.org.uk 